\title{
Uso de Macromoléculas sobre la Tasa de Maduración y Desarrollo Embrionario in vitro de Ovocitos Bovinos
}

\author{
Use of Macromolecules on the Rate of in Vitro Maturation and Embryonic \\ DEVELOPMENT OF BOVINE OOCYTES
}
Carolina Santa Cruz P. ${ }^{1}$, Wilfredo Huanca L. ${ }^{1,3}$, Rosario Condori P. ${ }^{1}$, Antonio Ampuero B. ${ }^{2}$

\section{Resumen}

Se evaluó el efecto de cuatro suplementos de macromoléculas sobre la tasa de maduración nuclear, división de ovocitos a las 48 horas y desarrollo embrionario a los siete días posfecundación. Se colectaron ovarios de camal, se aspiraron los folículos y se seleccionaron los ovocitos con dos o más capas de células para ser madurados en medio TCM-99 enriquecido con macromoléculas: Polivinil pirrolidona (PVP), Polivinil alcohol (PVA), Albúmina sérica bovina (BSA), Suero fetal bovino (SFB). Los ovocitos se cultivaron a $39^{\circ} \mathrm{C}$ y con $5 \%$ de $\mathrm{CO}_{2}$. Se evaluó la maduración nuclear a las 24 h, calificándolos como vesícula germinal, metafase I, anafase-telofase, metafase II y degenerados. Para evaluar la división y desarrollo embrionario, otro grupo de ovocitos fueron madurados bajo las mismas condiciones y fecundados por $18 \mathrm{~h}$ en medio de cultivo KSOM-AA, y trasferidos al medio de cultivo SOF por $48 \mathrm{~h}$. Solo hubo diferencias estadísticas en maduración nuclear (Metafase II) entre los grupos suplementados con PVA y SFB ( $\mathrm{p}<0.05)$. Asimismo, no hubo diferencias entre tratamientos en la tasa de división y desarrollo embrionario. Los resultados indican que los suplementos de macromoléculas proporcionan condiciones y requerimientos similares para la progresión desde estadios de metafase I a metafase II.

Palabras clave: maduración in vitro, ovocitos bovinos, fecundación in vitro

\footnotetext{
${ }^{1}$ Laboratorio de Reproducción Animal, ${ }^{2}$ Laboratorio de Zootecnia y Producción Agropecuaria, Facultad de Medicina Veterinaria, Universidad Nacional Mayor de San Marcos, Lima, Perú

${ }^{3}$ E-mail: whuanca2002@yahoo.com
} 
The effect of four supplements with macromolecules on the rate of nuclear maturation, oocyte division at $48 \mathrm{~h}$ and embryo development at 7 days post-fertilization was evaluated. Ovaries were collected in the slaughterhouse; oocytes with two or more layers of cells were selected and matured on TCM-99 enriched with macromolecule supplements: Polyvinylpyrrolidone (PVP), polyvinylalcohol (PVA), Bovine serum albumin (BSA), Foetal bovine serum (SFB). Oocytes were cultivated at $39^{\circ} \mathrm{C}$ with $5 \%$ of $\mathrm{CO}_{2}$. Nuclear maturation was evaluated at 24 hours, classifying them as germinal vesicle, metaphase I, anaphasetelophase, metaphase II and degenerated. For the evaluation of the oocyte division and embryo development, oocytes were matured under the same conditions and fertilized with spermatozoa during 18 hours in KSOM-AA culture media, and then transferred to SOF culture media for $48 \mathrm{~h}$. Significant differences on nuclear maturation (Metaphase II) were only observed between PVA and SFB $(p<0.05)$. Furthermore, none significant differences on rate of division and embryonic development between treatments were observed. These results indicate that the macromolecule supplements provide similar conditions and requirements for the progression from metaphase I to metaphase II.

Key words: in vitro maturation, bovine oocytes, in vitro fecundation

\section{INTRODUCCIÓN}

Las estrategias para incrementar la eficiencia de producción in vitro de embriones aún no están debidamente desarrolladas. Entre los varios factores asociados, se encuentran los medios de cultivo y las técnicas que influyen en este procedimiento, destacándose la importancia del uso de suplementos de macromoléculas y de las condiciones atmosféricas.

Los suplementos de macromoléculas más frecuentemente empleados en la producción de embriones in vitro incluyen la albúmina sérica bovina (BSA) y el suero fetal bovino (SFB). Estos suplementos son partículas coloides que facilitan el transporte de fluidos a través de la membrana celular (Webster, 1982), mejorando la maduración y desarrollo embrionario (Carolan et al., 1995). BSA y SFB actúan como quelantes de iones de metales pesados, en la barrera de $\mathrm{pH}$ como surfactantes y reaccionan con especies oxígeno dependientes (Orsi y Leese, 2004; Stein, 2007). Estos elementos favorecen la expan- sión de las células del cumulus y la producción de factores que promueven el reinicio de la meiosis (Eppig et al., 1983; Fukui y Ono, 1989; Sanbuissho y Threlfall, 1989; Lee et al., 1996). El BSA posee más de 1000 componentes, incluyendo factores de crecimiento y hormonas (Stein, 2007), e incrementa intracelularmente los aminoácidos libres luego de la hidrólisis (Orsi y Leese, 2004). Debido a esas características, es difícil obtener sustitutos para estos dos coloides en el cultivo de embriones.

BSA y SFB son productos de origen animal, de allí que su composición no es del todo conocida, presentando una gran variabilidad entre fabricantes y lotes (McKiernan y Bavister, 1992), además de existir el riesgo de transmisión de enfermedades (Krisher et $a l .$, 1999). Por estas razones, se puede decir que el medio de cultivo suplementado con BSA y SFB es parcialmente definido o indefinido en composición, siendo una fuente de variación en el sistema de cultivo y en los resultados que se pueden obtener (Bavister, 1995; Krisher et al., 1999). Es así que con el fin de estandarizar los procedimientos de desa- 
rrollo embrionario in vitro y evitar la transmisión de patógenos se vienen empleando fuentes sintéticas y definidas de suplementos, entre ellos, el polivinil alcohol - PPVA (Fukui et al., 2000) y polivinil pirrolidona PVP (Chung et al., 2007).

Los programas de maduración in vitro (MIV) y fertilización in vitro (FIV) buscan la producción de embriones de alta calidad, es decir, que tengan la capacidad de producir una gestación normal y de nacidos vivos al realizarse la transferencia a las receptoras. Para esto, un primer paso es la evaluación de las variables y factores que puedan contribuir al éxito de la técnica, como el uso de suplementos de fácil acceso y reducido costo en el medio de maduración, sin afectar la eficiencia de los resultados.

Por tanto, el objetivo del presente estudio fue estimar la eficiencia de dos medios definidos como los dos suplementos de macromoléculas (PVP y PVA), en comparación con un medio semidefinido como el BSA y a un medio indefinido como el SFB en el medio de maduración de ovocitos, así como determinar la tasa de división y desarrollo embrionario de estos ovocitos.

\section{Materiales y Métodos}

\section{Obtención de Ovocitos}

Se trabajó con vacas beneficiadas en el Camal de Yerbateros, ubicado en el distrito de Ate, provincia y departamento de Lima, Perú. Se colectaron los ovarios inmediatamente después del sacrificio, se colocaron en un termo conteniendo una solución salina $0.9 \%$ con antibióticos y antimicóticos (kanamicina, penicilina y gentamicina), a $37{ }^{\circ} \mathrm{C}$ y se trasladaron al Laboratorio de Reproducción Animal de la Facultad de Medicina Veterinaria, Universidad Nacional Mayor de San Marcos, Lima.
En el laboratorio se procedió a la aspiración de folículos que tenían entre 2 a $6 \mathrm{~mm}$ de diámetro, utilizando agujas $18 \mathrm{G} 11 / 2$ " y jeringas estériles de $10 \mathrm{ml}$. Los ovocitos se evaluaron en un estereomicroscopio y se clasificaron según Baez et al. (2008), donde Grado 1 son ovocitos con más de 3 capas de células de cumulus y citoplasma homogéneo, Grado 2 aquellos con 2 a 3 capas y citoplasma homogéneo, Grado 3, aquellos con pérdida parcial de células con vacuolas o citoplasma homogéneo, y Grado 4 los ovocitos desnudos o con cumulus expandido. Para efectos del estudio, solo se utilizaron ovocitos de grado $1 \mathrm{y}$ 2, llegando a recuperarse 2372 ovocitos aptos para ser utilizados.

\section{Fase 1: Maduración Nuclear}

En esta fase se evaluaron las macromoléculas PVA, PVP, BSA y SFB. Se emplearon 692 ovocitos distribuidos al azar en los cuatro tratamientos. Los ovocitos se colocaron en el medio de maduración TCM199 que fue enriquecido, según Fukui et al. (2000), Chung et al. (2007) y Stein (2007), con $6 \mathrm{mg} / \mathrm{ml}$ de cada uno de los suplementos de macromoléculas en estudio: T1 con PVP $(\mathrm{n}=176), \mathrm{T} 2$ con PVA $(\mathrm{n}=171), \mathrm{T} 3$ con BSA $(n=172)$ y T4 con SFB $(n=173)$. Los ovocitos fueron madurados por $24 \mathrm{~h}$ en condiciones de $38.5^{\circ} \mathrm{C}, 5 \%$ de $\mathrm{CO}_{2}$ y máxima humedad.

El grado de maduración de los ovocitos se determinó al término de la incubación en base al criterio de expansión de las células del cúmulo. Posteriormente, los ovocitos fueron colocados en una solución buffer - PBS (fosfato salino buffer) para proceder a su denudación, retirándoles las células del cúmulo, y luego fueron colocados en una solución de fijación etanol / ácido acético (3:1) por $36 \mathrm{~h}$.

Una vez retirados los ovocitos de la solución de fijación, se colocaron en un portaobjeto adicionando orceína para su tinción y llevados a un microscopio para de- 
terminar la fase de maduración nuclear, pudiendo ser vesícula germinal (VG), metafase I (MI), anafase-telofase I, metafase II (MII) y degenerados.

\section{Fase 2: Tasa de División y Desarrollo Embrionario}

En esta fase, 1680 ovocitos fueron distribuidos en los cuatro tratamientos anteriores; siendo T1 con PVP $(n=422), T 2$ con PVA $(n=420), T 3$ con BSA $(n=414)$ y T4 con SFB $(n=424)$. Los ovocitos fueron sometidos a un procedimiento similar a la Fase 1 hasta llegar a la etapa de maduración. Luego fueron fecundados con semen congelado de un solo toro, proveniente del mismo lote de colección y evaluado previamente por características de motilidad mayor de 50\% y con una concentración de espermatozoides mayor de 40 millones $/ \mathrm{ml}$.

Para la fecundación in vitro, el semen se colocó en una gradiente de Percoll (45/90) y luego se agregó al medio de fecundación conjuntamente con penicilamina, hipotaurina y epinefrina. Los ovocitos se retiraron a las 18 $\mathrm{h}$ de la fecundación y fueron desnudados mediante vorteo y de allí pasados a medio de cultivo KSOM-AA. La división de los presuntos gametos se evaluó a las $48 \mathrm{~h}$ posfecundación con ayuda de un estereomicroscopio. Los gametos fueron colocados en medio de cultivo SOF (fluido sintético de oviducto), donde se esperó hasta los siete días posfecundación para evaluar el desarrollo embrionario a blastocisto.

\section{Análisis Estadístico}

Los resultados obtenidos se expresaron como porcentajes dentro de cada grupo experimental. Se utilizó el Chi cuadrado para evaluar las diferencias entre tratamientos (suplementos de macromolécula) como variables cualitativas, mediante el programa SPSS v. 15.

\section{Resultados y Discusión}

La presencia del primer corpúsculo polar, indicando el estadio de metafase II (Fig. 1) se presentó en el $42.6,45.0,40.7$ y $37.7 \%$ en los tratamientos PVP, PVA, BSA y SFB, respectivamente (Cuadro 1).

Es importante indicar que la variabilidad de los resultados en la recolección de ovocitos se encuentra afectada por la experiencia del operador, el método utilizado para la recolección y por las características propias de los ovarios (edad, raza y estado reproductivo del animal). Para lograr una efectiva MIV es necesario tener en cuenta la calidad de los ovarios y de los ovocitos (Rodríguez et al., 2004). Asimismo, Leibfried y First (1979) señalan que la capacidad de MIV de los ovocitos bovinos no depende del momento del ciclo estrual en que son colectados. Por otro lado, la apariencia de la superficie de los folículos ha sido propuesta para pre-seleccionar los futuros ovocitos, mejorar los índices de maduración y FIV, así como para poder clasificarlos por categorías (Grimes e Ireland, 1986).

En el segundo experimento, la división a las 48 h de la fecundación (Fig. 2a) ocurrió mayormente con las macromoléculas PVA y PVP (59.3 y $58.4 \%$, respectivamente); mientras que en el desarrollo embrionario hasta blastocisto (Fig. 2b), los mayores porcentajes se observaron con SFB y BSA (43.2 y $42.3 \%$, respectivamente, Cuadro 2 ).

La fase de maduración tiene un gran impacto sobre las fases subsiguientes en los protocolos de fecundación in vitro, debido a que si existe una adecuada maduración del ovocito, sustentada en los cambios moleculares a nivel nuclear y citoplasmático, se va a favorecer la fecundación y el posterior desarrollo de los zigotos (Bavister, 1995). 


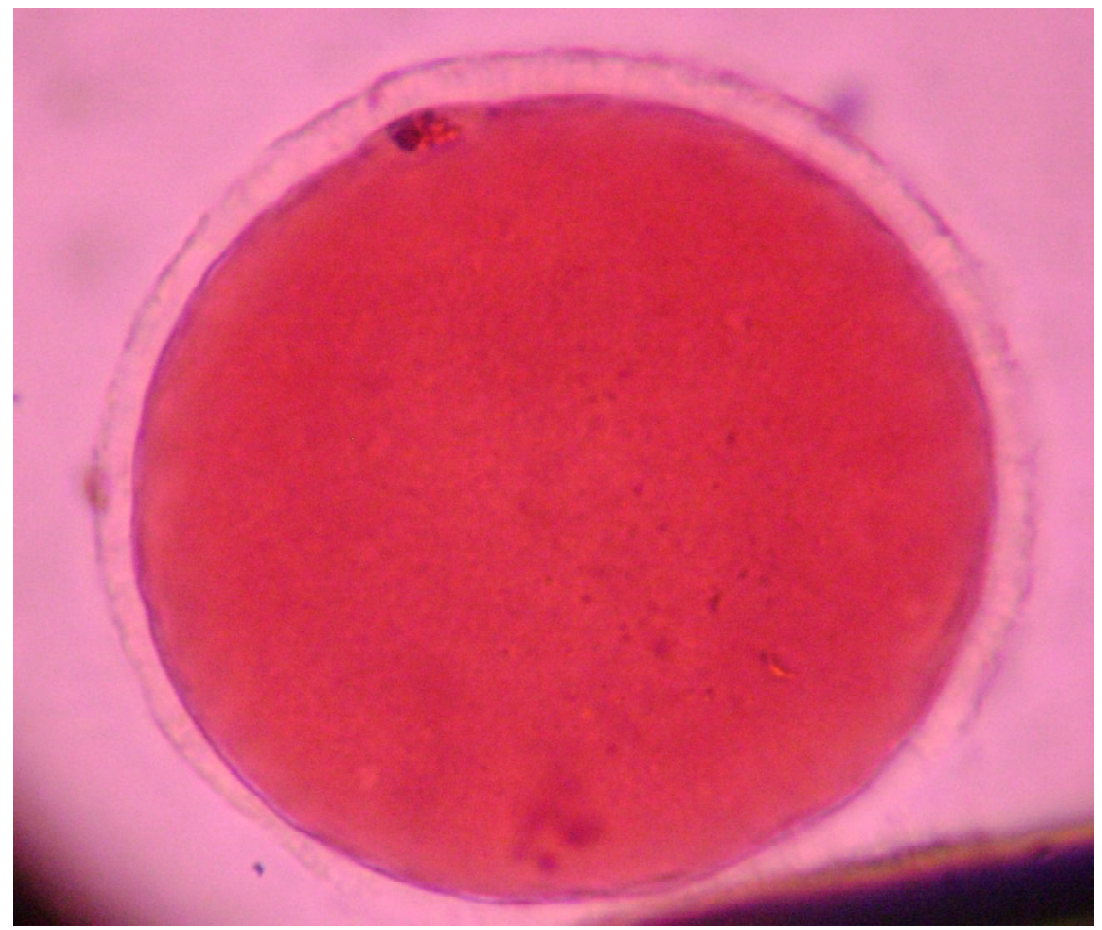

Figura 1. Presencia del primer corpúsculo polar (estadio de Metafase II) en ovocito de bovino

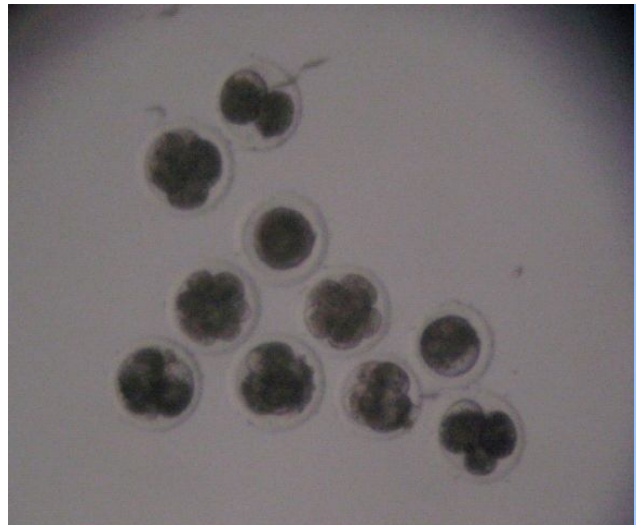

(a)

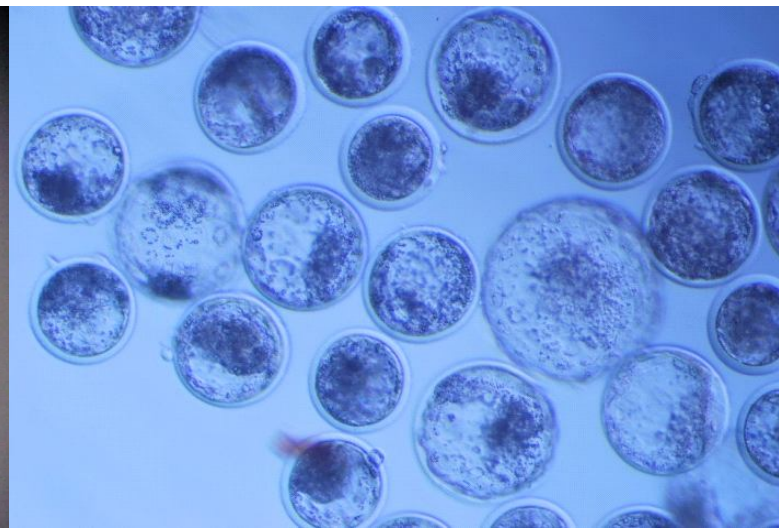

(b)

Figura 2. Ovocitos de bovino fecundados. a) División celular a las 48 h posfecundación. b) Blastocisto 
Cuadro 1. Tasa de maduración nuclear (Metafase II) de ovocitos de bovino empleando un medio de maduración con cuatro suplementos de macromoléculas

\begin{tabular}{lccccc}
\hline $\begin{array}{l}\text { Suplemento de } \\
\text { macromolécula }^{1}\end{array}$ & $\begin{array}{c}\text { Vesícula } \\
\text { germinal } \\
(\%)\end{array}$ & $\begin{array}{c}\text { Metafase I } \\
(\%)\end{array}$ & $\begin{array}{c}\text { Anafase- } \\
\text { Telofase I } \\
(\%)\end{array}$ & $\begin{array}{c}\text { Metafase II } \\
(\%)\end{array}$ & $\begin{array}{c}\text { Degenerado } \\
(\%)\end{array}$ \\
\hline PVP $(\mathrm{n}=176)^{2}$ & $13.7 \pm 1.8$ & $18.1 \pm 2.6$ & $19.3 \pm 2.8$ & $42.6^{\mathrm{a}, \mathrm{b}} \pm 3.6$ & $6.3 \pm 1.9$ \\
PVA (n=171) & $15.3 \pm 2.8$ & $21.1 \pm 0.8$ & $12.9 \pm 1.3$ & $45.0^{\mathrm{a}} \pm 1.7$ & $5.7 \pm 2.2$ \\
BSA (n=172) & $18.1 \pm 2.2$ & $18.0 \pm 2.0$ & $14.5 \pm 2.5$ & $40.7^{\mathrm{a}, \mathrm{b}} \pm 4.2$ & $8.7 \pm 0.9$ \\
SFB (n=173) & $21.9 \pm 1.4$ & $17.9 \pm 4.2$ & $15.6 \pm 1.2$ & $37.7^{\mathrm{b}} \pm 3.0$ & $6.9 \pm 1.4$ \\
\hline${ }^{1}$ PVP: Polivinil pirrolidona; PVA: Polivinil alcohol; BSA: Albúmina sérica bovina; SFB: Suero fetal \\
bovino
\end{tabular}

Cuadro 2. Tasa de división de ovocitos y desarrollo embrionario posfecundación

\begin{tabular}{cccc}
\hline $\begin{array}{c}\text { Suplemento de } \\
\text { macromolécula }^{1}\end{array}$ & $\begin{array}{c}\text { Número de } \\
\text { ovocitos }\end{array}$ & $\begin{array}{c}\text { División celular a las } \\
48 \text { horas }(\%)\end{array}$ & $\begin{array}{c}\text { Blastocistos a los 7 días } \\
(\%)\end{array}$ \\
\hline PVP & 422 & $59.3 \pm 6.4$ & $40.7 \pm 6.4$ \\
PVA & 420 & $58.4 \pm 6.0$ & $41.6 \pm 6.0$ \\
BSA & 414 & $57.7 \pm 2.7$ & $42.3 \pm 2.7$ \\
SFB & 424 & $56.8 \pm 2.9$ & $43.2 \pm 2.9$ \\
\hline
\end{tabular}

${ }^{1}$ PVP:Polivinil pirrolidona; PVA: Polivinil alcohol; BSA: Albúmina sérica bovina; SFB: Suero fetal bovino

\section{ConClusiones}

- El porcentaje de maduración in vitro de ovocitos procedentes de ovarios de vacas beneficiadas fue similar entre los tres suplementos de macromoléculas (polivinil pirrolidona, polivinil alcohol y albúmina sérica bovina), lo que sugiere su utilización para sustituir al Suero Fetal Bovino.

- El porcentaje de ovocitos con división posfecundación y con desarrollo embrionario fue similar entre tratamientos.

\section{Literatura Citada}

1. Bavister BD. 1995. Culture of preimplantation embryos: facts and artifacts. Hum Reprod Update 1: 91-148.

2. Carolan $C$, Lonergan P, Van Langenonckt A, Mermillod P. 1995. Factors affecting bovine embryo development in syntethic oviduct fluid following oocyte maturation and fertilization in vitro. Theriogenology 43: 1115-1128. 
3. Chung JT, Tosca L, Huang TH, Xu L, Niwa K, Chian RC. 2007. Effect of polyvinylpyrrolidone on bovine oocyte maturation in vitro and subsequent fertilization and embryonic development. Reprod Biomed Online 15: 198-207. doi: 10.1016/S1472-6483(10)60709-2

4. Eppig JJ, Freter R, Ward-Bailey PF, Schultz RM. 1983. Inhibition of oocyte maturation in the mouse: participation of cAMP, steroid hormones, and a putative maturation-inhibitor factor. Dev Biol 100: 39-49.

5. Fukui Y, Ono H. 1989. Effects of serum, hormones and granulosa cells added to culture medium for in vitro maturation, fertilization, cleavage and development of bovine oocytes. J Reprod Fert. 86: 501-506.

6. Fukui Y, Kikuchi Y, Kondo H, Mizushima S. 2000. Fertilizability and developmental capacity of individually cultured bovine oocytes. Theriogenology 53: 1553-1565. doi: 10.1016/S0093691X(01)00492-7

7. Grimes RW, Ireland JJ. 1986. Relationship of macroscopic appearance of the surface of bovine ovarian follicles, concentration of steroids in follicular fluid and maturation of oocytes in vitro. Biol Reprod 35: 725-732.

8. Krisher RL, Lane M, Bavister BD. 1999. Developmental competence and metabolism of bovine embryos cultured in semi-defined and defined culture media. Biol Reprod 60: 1345-1352.
9. Lee ES, Fujii Y, Fukui Y. 1996. A comparative study on developmental capacity to blastocysts derived from 1and 2(3)-cell bovine embryos after in vitro maturation and fertilization. Theriogenology 45: 1151-1162.

10. Leibfried L, First NL. 1979. Characterization of bovine follicular oocytes and their ability to mature in vitro. J Reprod Fert 48: 76-86.

11. McKiernan SH, Bavister BD. 1992. Different lots of bovine serum albumin inhibit or stimulate in vitro development of hamster embryos. In Vitro Cell Dev Biol 28A: 154-156.

12. Orsi NM, Leese HJ. 2004. Aminoacid metabolism of preimplantation bovine embryos cultured with bovine serum albumin or polyvinyl alcohol. Theriogenology 61: 561-572. doi: 10.1016/S0093691X(03)00206-1

13. Rodríguez LL, González A, Hayes $O$, Ramos B, Aguilar A, Castro FO. 2004. Clonación en animales mediante transferencia nuclear somática. Efecto de los factores biológicos. Biotecnol Apl 21: 137-146.

14. Sanbuissho A, Threlfall WR. 1989. The effects of estrous cow serum on the in vitro maturation and fertilization of the bovine follicular oocyte. Theriogenology 31: 693-699.

15. Stein A. 2007. Decreasing variability in yourcell culture. Biotechniques 43: 228-229.

16. Webster HL. 1982. Colloid osmotic pressure: theoretical aspects and background. Clim Perinatol 9: 505-521. 